growth variation, and (c) adopt a multidisciplinary approach to the study of human growth.

Three 'state of the art' lectures introduce the book. The first contribution by Professor Tanner entitled 'Growth as a mirror of the condition of society' is a fascinating historical review in addition to providing some provocative statements on the effect of present day unemployment on the health of the population. The other two lectures were concerned with childhood obesity and the relationship between nutrition/growth and longevity. The bulk of the book is a reproduction of the papers delivered during seven separate symposia. The symposium topics varied from biometrical aspects of growth (where an understanding of geometry and algebra is a distinct advantage), physiology of growth, growth and physical activity, to the pathology of growth. Certain topics such as the contribution by Wachtel on testicular differentiation (a clear exposé), Pollitt et al on anaemia and school achievement, and Girard et al on perinatal glucose homeostasis bear little relevance to the theme of the Congress, even when the multidisciplinary approach is considered. Other contributions worthy of mention include a practical and sensible approach to the child who is failing to thrive (Goldbloom) and a paper on chronogenetics in twins reared apart (Bronchard $e t$ $a l)$.

There is a wealth of data contained in this book for those interested in the wider issues of growth and its disorders. I do not know which professionals would benefit most from having a copy; certainly most geneticists will not regard this book as essential reading.

\section{A Hughes}

\section{Human Chromosomes. Structure, Behaviour, Effects \\ By Eeva Therman. (Pp 313; figures+tables. DM 47.) New York: Springer-Verlag. 1986.}

This book provides an introduction to human cytogenetics, enriched by references to animal and plant material where appropriate. Twenty-eight short chapters cover cell division, chromosome structure and behaviour, chromosome breakage, numerical and structural chomosome abnormality, chromosomes in cancer, and chromosome mapping. There are particularly useful chapters on allocycly, double minutes, and HSRs, topics rarely mentioned in other standard texts. As might be expected there is a good chapter on structural abnormalities of the $\mathrm{X}$ chromosome.
It would be an excellent book for undergraduates specialising in genetics, for medical students with an interest in human cytogenetics, and as an occasional reference book for clinical geneticists. Practising human cytogeneticists preparing for professional examinations will also find it useful as a reminder of the wide range of cytogenetic methods and mechanisms.

Its great virtue is that it gives succinctly the basic information on each topic, with a set of references to reviews and books, which make it easy to supplement the basic information in each chapter. Its lucid style makes it very easy to read and the clear subheadings in each chapter allow easy reference.

The book is well presented and adequately indexed. The quality of diagrams and illustrations is usually good, although it is unfortunate that some of the chromosome abnormalities, for example translocation and inversion, are only illustrated diagrammatically. Others come from unbanded material, for example, the pictures of chromosome 5 deletions, and some, such as the cases of trisomy 13 and trisomy 8 , show only poorly reproduced $\mathrm{Q}$ banding.

It is reasonably priced at $47 \mathrm{DM}$ (about $£ 15$ at current exchange rates) and there is enough that is new, in this second edition, to make this book a good buy even for those who already have the first edition.

P COOKE

\section{Human Cytogenetics: A Practical Approach}

Edited by D E Rooney and B H Czepulkowski. (Pp 232; figures+tables. £15.50.) Oxford: IRL Press, 1986.

This book, as the title implies, deals primarily with the methodology of human cytogenetics, but includes sufficient theory for the reader to understand the basic principles upon which the techniques are based. The volume is probably unique in containing protocols for nearly all the techniques encountered in clinical cytogenetics laboratories and some from more specialised areas.

Chapters $1,2,3$, and 5 describe a variety of culture and harvest techniques for lymphocytes, amniotic fluid cells, chorionic villi, fibroblasts, and bone marrow and other tissues from human malignancies, together with a wide range of staining methods. Chapter 4 differs conspicuously in addressing the rather more theoretical and less easily defined topic of 'analysis and interpretation'. On the whole, this chapter is well balanced and informative, 
but the advocacy of 'intuitive nomenclature', which is particularly inappropriate in this context, is disappointing.

The remainder of the book is concerned with techniques that are largely research orientated. The penultimate chapter describes those involved in the study of meiosis in man and discusses their application, while the last chapter summarises techniques that have been widely used in gene mapping and as adjuncts to DNA technology but are rarely applied in the clinical cytogenetics laboratory, namely, in situ hybridisation, somatic cell fusion, and flow cytometry. The authors consider the latter to be the most promising automated system for detailed analysis of the human karyotype. Strangely, there is no mention anywhere of the computerised image analysis systems, which many would regard as having more potential.

In recent years there has been a profusion of cytogenetic techniques, most of which have now been included in this one volume. The uninitiated, however, would do well to reflect on the axiom that for most techniques there are as many protocols as there are laboratories and that modification is generally a necessity. Nevertheless, this volume is a timely, well presented, and useful publication. The experienced worker will, perhaps, only refer to it occasionally, but researchers, those in the early stages of their careers, and those studying for examinations will find it an unrivalled source of technical information and very good value for money.
Leukemia: Recent Advances in Biology and Treat ment

Edited by R P Gale and D W Golde. (Pp 74 figures + tables.) New York: Alan R Liss. 1985.

This book is one of the series of UCLA Symposia o molecular and cellular biology, and reports recere advances in the biology and treatment of leukaemia Fifty original contributions and summaries of three workshops are grouped in chapters dealing with oncogenes and chromosomes, viruses, growth fa $\vec{\xi}$ tors and receptors, stem cells, pathogenesis $\mathbb{S}$ leukaemia, pharmacology, and therapy. The rapi] advances, especially in the first three fields, ares comprehensively covered. While relevant to haemat tologists and oncologists as a source of basis information, they will be of more interest to cell an molecular biologists and other research workersi The last two chapters are more relevant to those dealing with the therapy of leukaemia and provide good reviews of current information.

In some chapters, a welcomed effort has bee made to put such information in perspective witt regard to the evaluation of present trends ip treatment, and the better ways to go forward.

The style of presentation reflects the persona preferences of the authors, as is often seen i proceedings of symposia. Some contributions follo the format of original research papers, and a fee give reviews of their subject matter. The print reade format may be hard on some eyes, but that should not deter potential readers interested in this fasc nating field. 